\title{
Antimicrobial Activity of Hippurate Nanocomposite and Its Cytotoxicity Effect in Combination with Cytarabine against HL-60
}

\author{
Samer Hasan Hussein Al Ali, ${ }^{1}$ Mothanna Al-Qubaisi, ${ }^{1}$ Mohamed El Zowalaty, \\ Mohd Zobir Hussein, ${ }^{3}$ and Maznah Ismail ${ }^{1,4}$ \\ ${ }^{1}$ Laboratory of Molecular Biomedicine, Institute of Bioscience, Universiti Putra Malaysia, 43400 Serdang, Selangor, Malaysia \\ ${ }^{2}$ Laboratory of Vaccines and Immunotherapeutics, Institute of Bioscience, Universiti Putra Malaysia, \\ 43400 Serdang, Selangor, Malaysia \\ ${ }^{3}$ Materials Synhesis and Characterization Laboratory (MSCL), Institute of Advanced Technology, Universiti Putra Malaysia, \\ 43400 Serdang, Selangor, Malaysia \\ ${ }^{4}$ Department of Nutrition and Dietetics, Faculty of Medicine and Health Science, Universiti Putra Malaysia, \\ 43400 Serdang, Selangor, Malaysia
}

Correspondence should be addressed to Mohd Zobir Hussein; mzobir@putra.upm.edu.my

Received 27 August 2012; Revised 27 November 2012; Accepted 28 November 2012

Academic Editor: Xiliang Luo

Copyright (C) 2013 Samer Hasan Hussein Al Ali et al. This is an open access article distributed under the Creative Commons Attribution License, which permits unrestricted use, distribution, and reproduction in any medium, provided the original work is properly cited.

\begin{abstract}
Hippuric acid (HA) was intercalated into a zinc-layered hydroxide (ZLH) by direct reaction of an aqueous suspension of zinc oxide with an aqueous solution of hippuric acid to obtain hippurate nanocomposite (HAN). Various concentrations of hippuric acid $(0.05,0.2$, and 0.4 molar) were used for the synthesis of the nanocomposite. The as-synthesized HAN using 0.2 molar was found to give a well-ordered layered nanocomposite material with an increase in the basal spacing to $21.3 \AA$ which indicated the insertion of hippurate organic moiety into the ZLH interlayers. The cytotoxicity of HAN in combination with cytarabine against human promyelocytic leukemia cells (HL-60) was tested using MTT cell viability assay and trypan blue dye exclusion assay. The combination of cytarabine with HAN showed higher tumor suppression efficiency as compared to that of cytarabine alone. The $\mathrm{IC}_{50}$ values of HAN/cytarabine combination and cytarabine alone were $0.16 \pm 0.07 \mu \mathrm{g} / \mathrm{mL}$ and $0.17 \pm 0.09 \mu \mathrm{g} / \mathrm{mL}$, respectively. DNA fragmentation was also studied, and the exposure of HL-60 cells to cytarabine produced $10.70 \pm 0.96 \%$ DNA fragmentation compared to $18.90 \pm 1.33 \%$ when cells were exposed to combination of cytarabine with HAN. The antimicrobial activity of hippuric acid and HAN nanocomposite was carried out against Gram-positive bacteria, Gram-negative bacteria, and yeasts. It was found that Pseudomonas aeruginosa and methicillin-resistant Staphylococcus aureus were more sensitive to HAN compared to Bacillus subtilis and Salmonella choleraesuis.
\end{abstract}

\section{Introduction}

Metal hydroxide compounds can be classified according to their structures and chemical compositions into two groups. The first group is the layered double hydroxide (LDH) derived from the brucite structure $\left(\mathrm{Mg}(\mathrm{OH})_{2}\right)$ through substitution part of the divalent cations by the trivalent ones. As a result, the layers acquire excess positive charge, which is balanced by the incorporation of anions into the interlayer space. The general formula may be thus given as (LDH -
$\left.\mathrm{M}_{1-x}^{2+} \mathrm{M}_{x}^{3+}(\mathrm{OH})_{2}\left(\mathrm{~A}^{m-}\right)_{x / m} \cdot n \mathrm{H}_{2} \mathrm{O}\right)$, where $\mathrm{M}^{2+}$ is divalent cations, $\mathrm{M}^{3+}$ is trivalent cations, and $\mathrm{A}^{m-}$ is exchangeable anion with a charge $\left(\mathrm{m}^{-}\right)$[1]. The second group is the metal hydroxide compounds which are layered metal hydroxide salt (LHS) that can be represented by the general formula $\left(\right.$ LHS $\left.-\mathrm{M}^{2+}(\mathrm{OH})_{2-x}\left(\mathrm{~A}^{m-}\right)_{x / m} \cdot n \mathrm{H}_{2} \mathrm{O}\right)$ [2]. The interlayer anion exchangeable capability of LDH and LHS meets the requirement of inorganic layers for encapsulating organic drugs with negative charge and is used in drug delivery applications [3], as well as controlled release systems [4-7]. 
Zinc layered hydroxide (ZLH) is an example of the layered hydroxide salt in which zinc atoms are octahedrally coordinated with six hydroxide groups to give an empirical formula of $\mathrm{Zn}_{5}(\mathrm{OH})_{8}\left(\mathrm{NO}_{3}\right)_{2} \cdot 2 \mathrm{H}_{2} \mathrm{O}$ [8].

Our previous work showed that hippuric acid intercalated into zinc layered hydroxide potentiated the cytotoxicity of tamoxifen against hepatocellular carcinoma HepG2 [9]. The present study was conducted to investigate whether HAN could enhance the toxic effect for cytarabine, another chemotherapy used commonly to treat human promyelocytic leukemia. A parallel to that, antimicrobial activity of HAN nanocomposite against different micro-organisms was also determined.

\section{Materials}

Hippuric acid $\left(\mathrm{C}_{9} \mathrm{H}_{9} \mathrm{NO}_{3}\right)$ with $98 \%$ purity was purchased from Merck and was used as received. Cytarabine $\left(\mathrm{C}_{9} \mathrm{H}_{13} \mathrm{~N}_{3} \mathrm{O}_{5}\right)$ with $99 \%$ purity was purchased from Bioscience (Tocris, Bristol, UK). Zinc oxide of the American chemical society reagent grade was purchased from Fisher Scientific, and dimethyl sulfoxide (DMSO) was purchased from Ajax Finechem and used without further purification. Diphenylamine reagent containing $100 \mathrm{~mL}$ glacial acetic acid, $1.5 \mathrm{~g}$ diphenylamine, $1.5 \mathrm{~mL}$ concentrated sulfuric acid, and $0.5 \mathrm{~mL} 16 \mathrm{mg} / \mathrm{mL}$ acetaldehyde stock and trypan blue solution were purchased from Sigma-Aldich. The cell line HL60 was purchased from the American type culture collection (ATCC number CCL-240). Deionized water was used in all the experiments. The microbial strains were provided by the UNiCC, Institute of Bioscience, Universiti Putra Malaysia.

\section{Preparation of Hippurate Nanocomposite, HAN}

Hippurate nanocomposite (HAN) was synthesized by direct reaction using zinc oxide $(\mathrm{ZnO})$ as the starting material as reported previously [9-11]. The concentrations of hippuric acid of $0.05,0.2$, and 0.4 molar were prepared using appropriate weights of active material in $20 \mathrm{~mL}$ of DMSO and adjusting the final volume to $50 \mathrm{~mL}$ by the addition of deionized water. A weight of $0.2 \mathrm{~g}$ of zinc oxide was suspended in $50 \mathrm{~mL}$ water. Hippurate solutions were added slowly dropwise to the suspended zinc oxide, with vigorous stirring until the addition was completed and the solution became clear; the $\mathrm{pH}$ was adjusted to 7.9 using an aqueous solution of $\mathrm{NaOH}$ ( 0.5 molar). The resulting precipitate was magnetically stirred for 18 hours at $70^{\circ} \mathrm{C}$ and washed with deionized water. Finally, the as-synthesized HAN was dried in an oven at $60^{\circ} \mathrm{C}$ overnight and kept in a sample bottle for further characterizations.

\section{MTT Cytotoxicity Assay}

Human promyelocytic leukemia (HL-60) cells were used in the present study. Cells were routinely cultured at $37^{\circ} \mathrm{C}$ a humidified atmosphere with $5 \% \mathrm{CO}_{2}$ in 96 -well plates for 24 hours. When cells were grown up to $80 \%-90 \%$ of cellular confluence, the cells were treated with cytarabine alone and an equivalent cytostatic mixture of either hippuric acid or HAN. After 72 hours of incubation in a humidified atmosphere with $5 \% \mathrm{CO}_{2}$ at $37^{\circ} \mathrm{C}$, MTT assay with 3-(4,5-dimethylthiazole-2-yl)-2, 5-diphenyltetrazolium bromide was carried out with incubation times to determine the number of viable cells. Twenty microliters of MTT was added to all wells, and the cells were incubated for an additional 4 hours. After incubation, the upper part of the solution was removed to leave $30 \mu \mathrm{L}$ in all wells, and the formazan precipitate was dissolved in $10 \%$ sodium dodecyl sulfate in dimethyl sulfoxide containing $0.6 \%$ acetic acid. The microplates were then gently shaken in the dark for 30 minutes, and the absorbance at $570 \mathrm{~nm}$ and $630 \mathrm{~nm}$ (background) was measured spectrophotometrically using a microtiter plate reader. All experiments were carried out in triplicate. The $\mathrm{IC}_{50}$ was generated from the dose-response curves for the cell line. MTT assy of HL-60 cells treated with a combination of doxorubicin with hippuric acid and HAN was used as positive control.

\section{Antiproliferative Assay}

Human promyelocytic leukemia (HL-60) cells were used; the cells were seeded at a density of $1 \times 10^{5}$ viable cells $/ \mathrm{mL}$ in six-well plates. After incubation for 24 hours, the cells were treated with cytarabine $(0.5 \mu \mathrm{g} / \mathrm{mL})$ alone and its combination with hippuric acid or HAN. The plates were incubated at $37^{\circ} \mathrm{C}$ in the presence of $5 \% \mathrm{CO}_{2}$, for 24,48 , and 72 hours. After incubation, the media were aspirated off, and cells were washed with cold PBS buffer to get rid of dead cells and replaced with $1 \mathrm{~mL}$ of $0.05 \%$ trypsin-EDTA $(2 \mathrm{mg} / \mathrm{mL})$. The plates were incubated at $37^{\circ} \mathrm{C}$ for $10-15$ minutes, until the majority of the cells were detached. The cells were harvested, and the cell suspension was centrifuged at $1000 \mathrm{rpm}$ for 10 minutes, and the supernatant discarded. Twenty microliters of cell suspension was mixed with $20 \mu \mathrm{L}$ of $0.4 \%$ trypan blue solution. Cells were resuspended, and dyeexcluding viable cells were microscopically counted using a hemocytometer.

\section{Examination of DNA Fragmentation}

DNA fragmentation was quantitatively determined using diphenylamine reagent for cells treated with $1 \mu \mathrm{g} / \mathrm{mL}$ cytarabine alone and in equal combination with either $1 \mu \mathrm{g} / \mathrm{mL}$ hippuric acid or $1 \mu \mathrm{g} / \mathrm{mL}$ HAN. A volume of $108 \mu \mathrm{L}$ of 5 molar perchloric acid was added, and samples were heated at $70^{\circ} \mathrm{C}$ for $15 \mathrm{~min}$. Two volumes of a solution containing diphenylamine reagent were added, and the samples were stored at $4^{\circ} \mathrm{C}$ for 48 hours. The colorimetric reaction was determined spectrophotometrically at $575 \mathrm{~nm}$ using a UV spectrophotometer (UV-160A; Shimazu Co. Ltd., Tokyo, Japan). DNA aliquots from both pellet and supernatant were quantified. The degree of DNA fragmentation referred to the percentage of DNA in the supernatant divided by the total DNA from the pellet and supernatant was determined. 


\section{Microbial Strains and Cultural Conditions}

Four well-characterized species of bacteria including two Gram-positive micro-organisms: methicillin-resistant Staphylococcus aureus (MRSA) and Bacillus subtilis and two Gram-negative species: Salmonella choleraesuis and Pseudomonas aeruginosa, and yeast: Candida albicans were used in the screening of the synthesized HAN. Cultures were maintained on Luria-Bertani (LB) agar (1st Base, Singapore) or potato dextrose agar in case of yeast. Prior to incubation with nanoparticles, the bacteria were cultured overnight in $5 \mathrm{~mL}$ of LB broth (1st Base, Singapore) in a Certomat SII incubation shaker (Sartorius Stedim Biotech, Aubagne, France) at $37^{\circ} \mathrm{C}$ and $150 \mathrm{rpm}$ until the culture reached an $\mathrm{OD}_{600}$ of 1.0 (Ultrospec UV VIS 3000 pro, Amersham Pharmacia Biotech, Cambridge, England) corresponding to approximately $10^{8} \mathrm{CFU} \mathrm{mL}^{-1}$. The overnight cultures were diluted to approximately $10^{7} \mathrm{CFU} \mathrm{mL}^{-1}$ using sterile $\mathrm{LB}$ broth.

\section{Antimicrobial Activity Testing}

The antimicrobial properties of the HAN nanocomposite were evaluated against the aforementioned micro-organisms using the disk diffusion method as described previously [12]. Microorganisms were cultured in LB broth in case of bacteria (1st Base, Singapore) or potato dextrose broth (Fluka) in case of yeast to achieve a culture growth turbidity of 1 by measuring optical density (OD) spectrophotometrically at $600 \mathrm{~nm}$. The suspension of each micro-organism was serially diluted in LB broth to a concentration of $1 \sim 210^{4} \mathrm{CFU} / \mathrm{mL}$. The inhibitory activity was read after 24 hours of incubation at $37^{\circ} \mathrm{C}$. HAN-free discs (distilled water only) cultured under the same conditions were used as a control.

\section{Characterization}

Powder X-ray diffraction patterns were recorded with a Shimadzu XRD-6000 instrument (Shimadzu, Tokyo, Japan) using $\mathrm{CuK} \alpha$ radiation $(\lambda=1.5418 \AA)$ and a dwell time of 4 degrees per minute. Cell count was carried using Neubauer hemocytometer (Weber, England) using clear field microscopy (Nikon, Japan). The bacteria were cultured overnight in a Certomat SII incubation shaker (Sartorius Stedim Biotech, Aubagne, France). UV spectrophotometer (UV-160A; Shimadzu Co. Ltd., Tokyo, Japan) was used in the determination of DNA fragmentation.

\section{Results and Discussion}

10.1. Powder X-Ray Diffraction. Figures 1(a) and 1(e) show PXRD patterns of the $\mathrm{ZnO}$ and free hippuric acid, respectively. In addition, Figures 1(b)-(d) show hippurate nanocomposites prepared using various concentrations of hippuric acid: $0.05,0.2$, and 0.4 molar, respectively. As shown in Figure 1(a), the $\mathrm{ZnO}$ sample shows five intense reflections between $30-60^{\circ}$ correspond to diffractions due to 100,002 , 101,102 , and 110 planes [13]. It was reported previously that the basal spacing for zinc layered hydroxide with nitrate

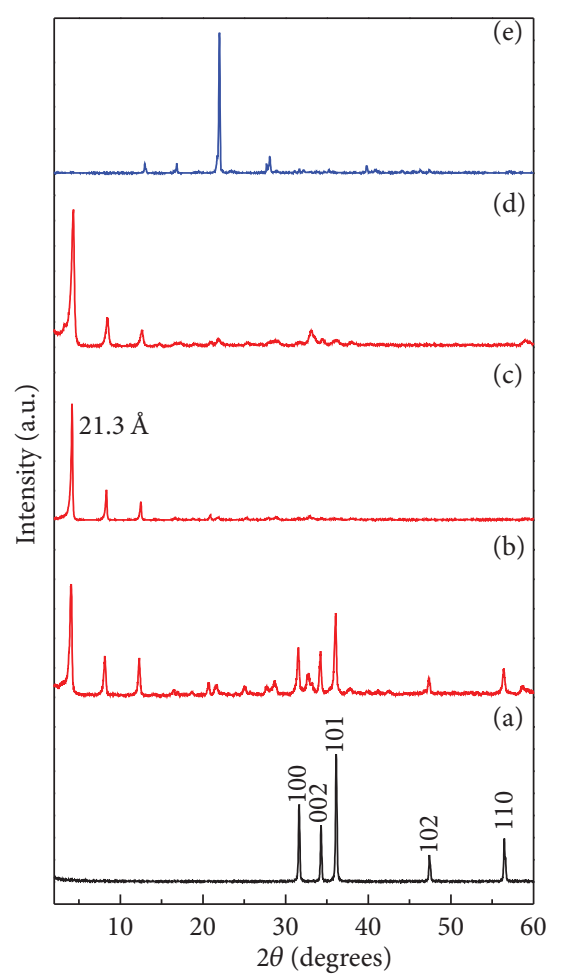

FIGURE 1: PXRD patterns for $\mathrm{ZnO}$ (a), hippurate nanocomposite prepared at various concentrations of hippuric acid $(0.05,0.2$, and 0.4 molar for (b), (c), and (d), resp.,) and free hippuric acid (e).

(ZLH) as the interlamella anion was $9.74 \AA$ which appeared at $2 \theta=9.12$ due to the 200 plane of the monoclinic structure [14]. The PXRD pattern for HAN is shown in Figure 2(c) with basal spacing of $21.3 \AA$. The expansion of basal spacing from ZLH to HAN was due to the inclusion of hippuric acid anion, namely, hippurate into the ZLH lamella with a vertical monolayer orientation that warrants the expansion of the ZLH lamella [9]. This can only be achieved when suitable concentration of hippuric acid is available in the mother liquor, under the experimental conditions as stated earlier. At Figure 1(d) HAN prepared using 0.4 molar hippuric acid, a number of peaks are observed due to hippuric acid phase. This might be due to the non-intercalated hippuric acid, which was adsorbed onto the surface of ZLH. HAN prepared using 0.05 molar hippuric acid shows the presence of $\mathrm{ZnO}$ phase. HAN prepared using 0.2 molar hippuric acid produced sharp, symmetrical, and intense peaks, especially for the (003) peak, and the relatively pure intercalated compound was obtained at this concentration. As a result of relatively pure phase, HAN prepared from 0.2 molar hippuric acid was subsequently used for further characterizations.

10.2. Cytotoxicity of Combination of HAN with Cytarabine. Figure 2 shows the cytotoxicity of hippuric acid, HAN nanocomposite, and their combinations with cytarabine against HL-60 cells. The cytotoxicity of cytarabine was investigated using human promyelocytic (HL-60) cells as described previosly [15]. The hippuric acid and HAN 


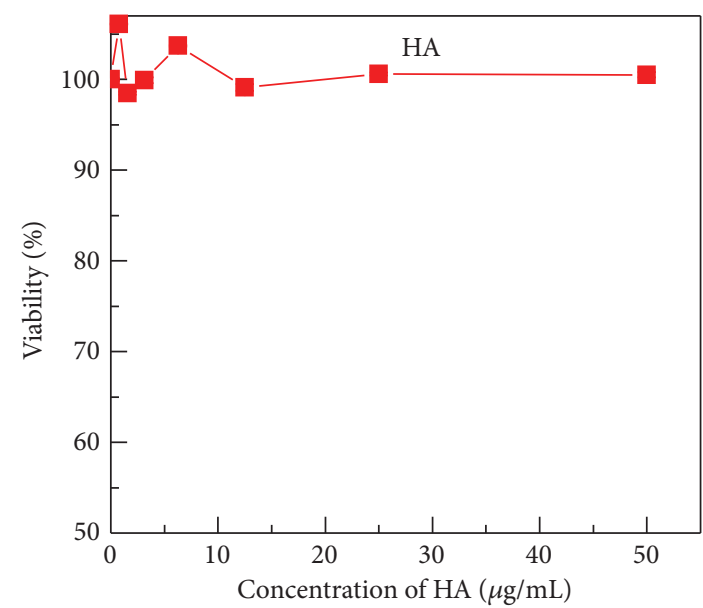

(a)

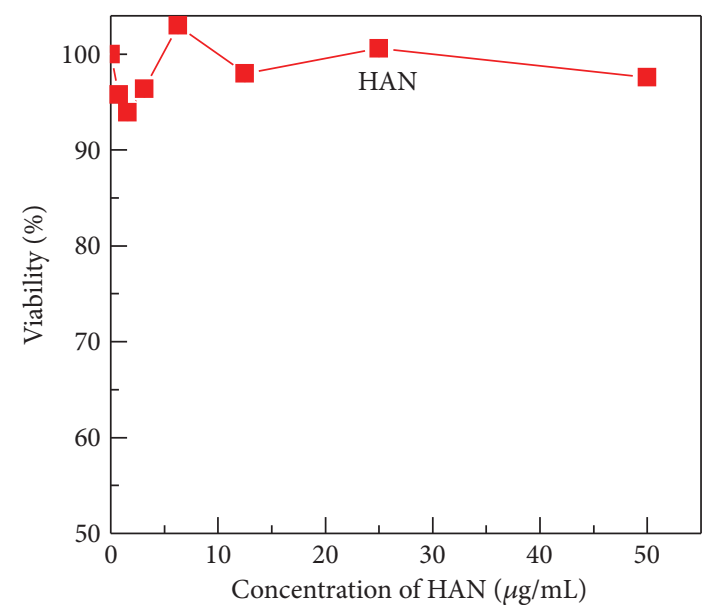

(b)

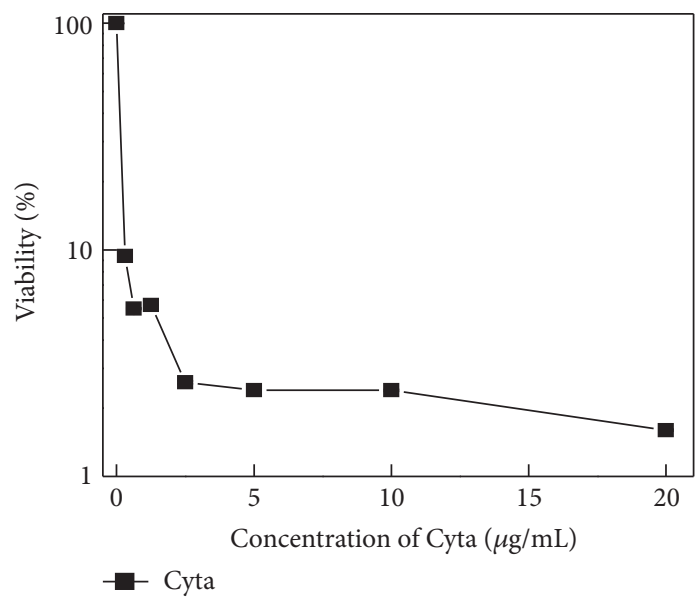

(c)

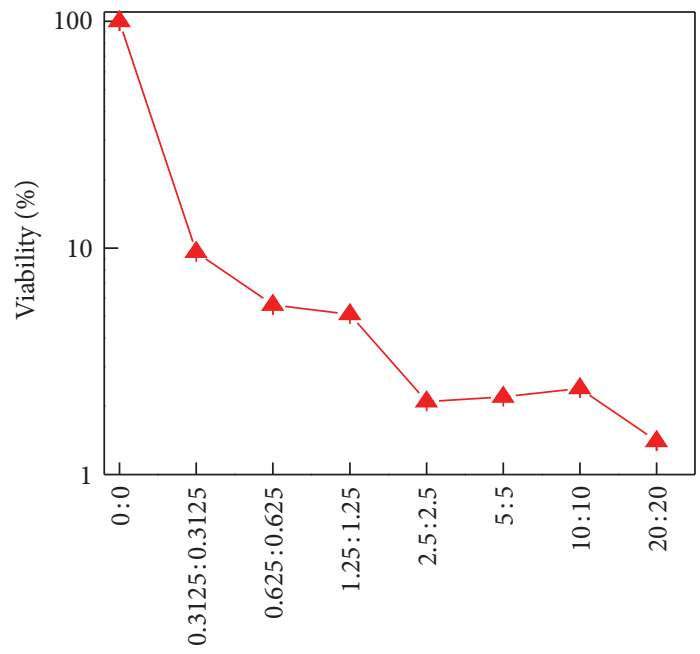

Concentration of Cyta with HA $(\mu \mathrm{g} / \mathrm{mL})$

- Cyta + HA

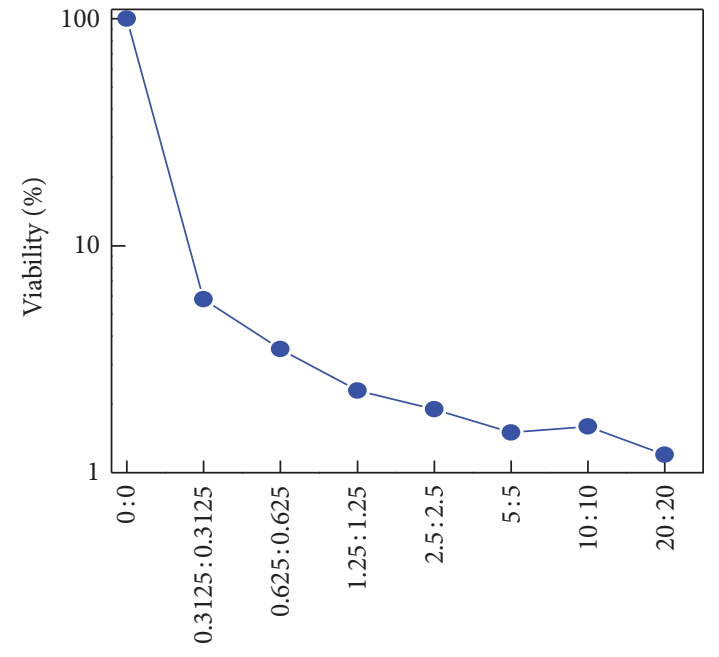

Concentration of Cyta with HAN $(\mu \mathrm{g} / \mathrm{mL})$

- Cyta + HAN

FIgURE 2: MTT assays of HL-60 cell line treated with free hippuric acid, HAN and the combination of cytarabine with hippuric acid and HAN. 
TABLE 1: Viability of HL-60 cells during incubation with cytarabine, combination of cytarabine with hippuric acid, and cytarabine with HAN nanocomposite.

\begin{tabular}{lccc}
\hline Concentration of Cyta $(\mu \mathrm{g} / \mathrm{ml})$ & Viability $(\%)$ & Concentration of Cyta : HA or HAN $(\mu \mathrm{g} / \mathrm{mL})$ & \multicolumn{2}{c}{ Viability $(\%)$} & HA & 1.4 \\
\hline 20.0 & 1.6 & $20: 20$ & 2.4 \\
10.0 & 2.4 & $10: 10$ & 1.2 \\
5.0 & 2.4 & $5: 5$ & 1.6 \\
2.5 & 2.6 & $2.5: 2.5$ & 2.2 \\
1.25 & 5.7 & $1.25: 1.25$ & 5.1 \\
0.625 & 5.5 & $0.625: 0.625$ & 1.9 \\
0.3125 & 9.4 & $0.3125: 0.3125$ & 2.3 \\
0.00 & 100.0 & $0: 0$ & 3.5 \\
\hline
\end{tabular}

TABLE 2: $\mathrm{IC}_{50}$ for HL-60 cells during incubation with cytarabine, doxorubicin, and combination of drugs with hippuric acid and with HAN nanocomposite.

\begin{tabular}{|c|c|c|c|c|c|c|}
\hline & \multicolumn{3}{|c|}{ Cytarabine } & \multicolumn{3}{|c|}{ Doxorubicin } \\
\hline & Cyta & Cyta + HA & Cyta + HAN & Doxo & Doxo + HA & Doxo + HAN \\
\hline $\mathrm{IC}_{50}$ & $0.17 \pm 0.09 \mu \mathrm{g} / \mathrm{mL}$ & $0.17 \pm 0.07 \mu \mathrm{g} / \mathrm{mL}$ & $0.16 \pm 0.07 \mu \mathrm{g} / \mathrm{mL}$ & $2.70 \pm 0.07 \mu \mathrm{g} / \mathrm{mL}$ & $1.80 \pm 0.11 \mu \mathrm{g} / \mathrm{mL}$ & $1.03 \pm 0.19 \mu \mathrm{g} / \mathrm{mL}$ \\
\hline
\end{tabular}

TABLE 3: Antiproliferative assays of HL-60 cells after 24, 48, and 72 hours treatment with cytarabine alone and combination of cytarabine with hippuric acid and HAN nanocomposite.

\begin{tabular}{lccr}
\hline Incubation time & & HL-60 & \\
& Cytarabine & Cytarabine + HA & $88.20 \%$ \\
\hline 24 hours & $83.50 \%$ & $82.40 \%$ & $95.10 \%$ \\
48 hours & $91.40 \%$ & $91.40 \%$ & $97.40 \%$ \\
72 hours & $95.50 \%$ & $95.10 \%$ & 9 Cytarabine + HAN \\
\hline
\end{tabular}

nanocomposite, up to a concentration of $50 \mu \mathrm{g} / \mathrm{mL}$ did not show any inhibition in the cell growth of treated HL-60 cells (Figures 2(a) and 2(b)). In the absence of hippuric acid or HAN (Figure 2(c)), the cytarabine suppressed the growth of HL-60 cells with $\mathrm{IC}_{50}$ values of $0.17 \pm 0.09 \mu \mathrm{g} / \mathrm{mL}$. As shown in Figure 2(d) and Table 1, the combination of hippuric acid with cytarabine show inhibition in the cell growth, similarly with cytarabine action and with $\mathrm{IC}_{50} 0.17 \pm 0.07 \mu \mathrm{g} / \mathrm{mL}$.

The combination of cytarabine with HAN (Figure 2(e)) shows slightly higher tumor suppression as compared to cytarabine alone with $\mathrm{IC}_{50}$ values of $0.16 \pm 0.07 \mu \mathrm{g} / \mathrm{mL}$. This indicate that the suppression percentage using HAN reached 4.1\%. A detailed look at Table 1, the results of MTT assay show that HAN exposure potentiates the toxic activity of cytarabine in HL-60 cells in a dose-dependent manner, and the lowest two combinations $(0.62 \mu \mathrm{g} / \mathrm{mL}$ and $0.31 \mu \mathrm{g} / \mathrm{mL})$ show the most notable effect.

Furthermore, compared with cytarabine, doxorubicin (Doxo) showed lower cytotoxicity toward the HL-60 cell line (Figures 3(a)-3(c)). Table 2 shows the $\mathrm{IC}_{50}$ values for the combination of cytarabine and doxorubicin with hippuric acid and HAN nanocomposite.

10.3. Antiproliferative Effect of Cytarabine Alone and Combinations of Cytarabine with Hippuric Acid and HAN. Figure 4(a) shows the effect of free cytarabine or in combination with hippuric acid and HAN on the proliferation of HL-60 cells at various incubation periods 24, 48, and 72 hours. Cytarabine and its combination with HAN suppressed the proliferation of HL-60 tumor cells. The combination of the drug with HAN was more efficient than the free drug in suppressing the tumor cells.

As shown in Table 3 at 24 hours, the combination of cytarabine with HAN showed $88.20 \%$ suppression of the proliferation as compared to the free cytarabine, which showed only $83.50 \%$ suppression. Additionally, at 72-hour treatment, the growth suppression for cytarabine with HAN showed $97.40 \%$, compared to $95.50 \%$ for free cytarabine.

The result in Figure 4(b) confirmed that the combination of cytarabine with HAN can inhibit the cell proliferation more than doxorubicin with HAN.

In general, the current study showed that HAN did not potentiate the toxicity of cytarabine. However, these results are clearly distinct from our previous findings with tamoxifen, in which HAN showed a dramatic inhibition of HepG2 cell proliferation [9].

10.4. Examination of DNA Fragmentation. DNA fragmentation is an important feature of nucleus that occurs in the apoptotic process. It is worth mentioning that Bouffard and Momparler have studied the effect of cytarabine versus DNA damages in leukemic cell HL60 line. Cytarabine at $5 \mu \mathrm{m}$ 


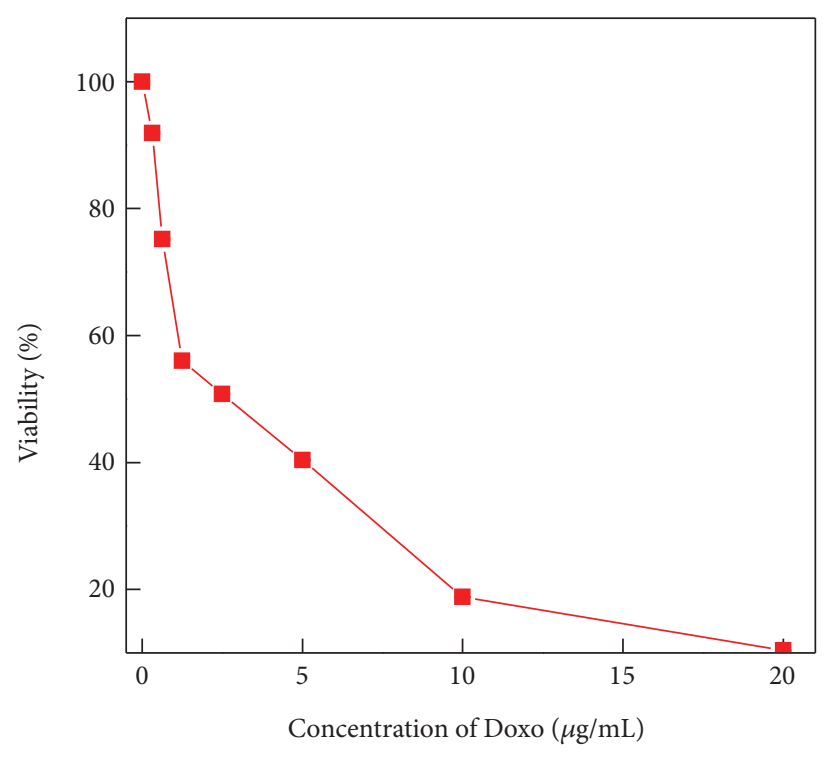

(a)

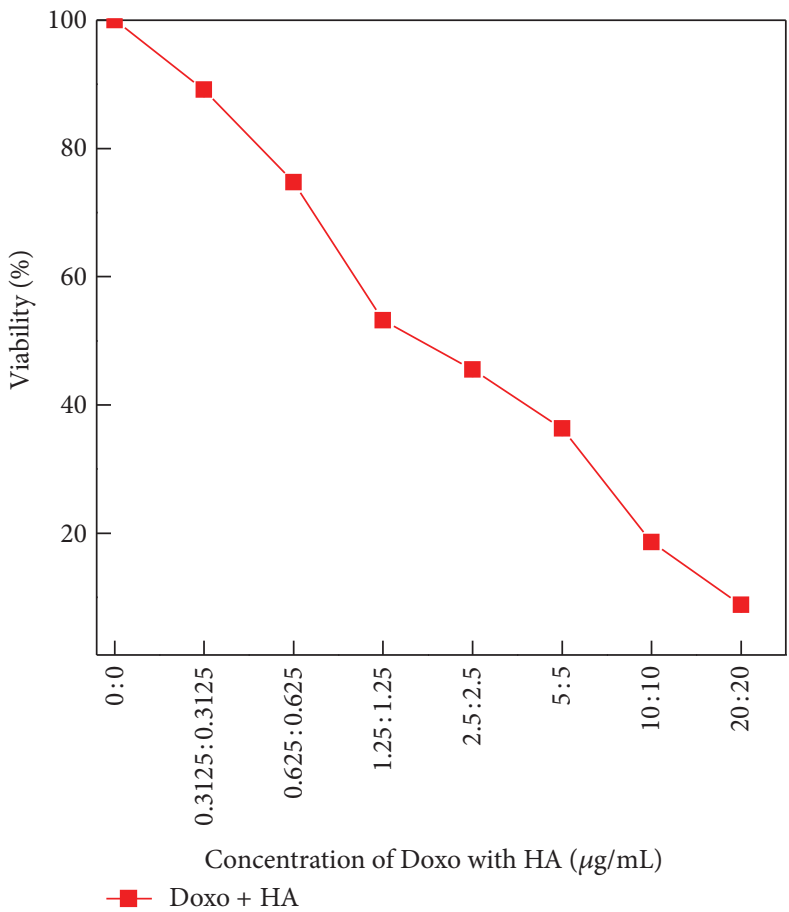

(b)

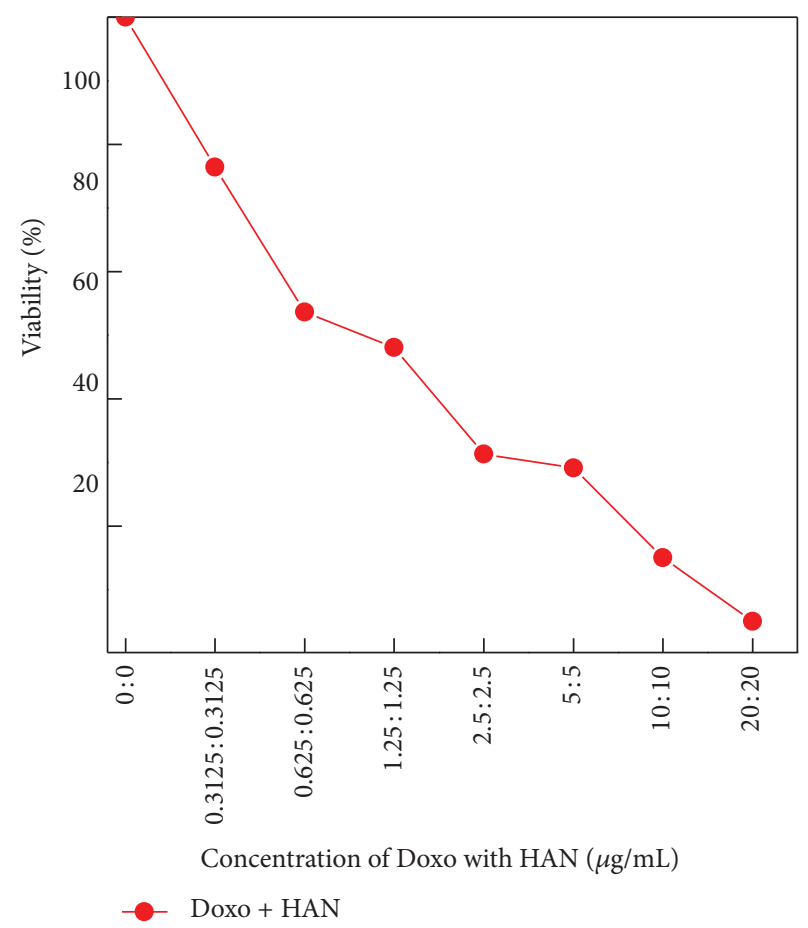

(c)

FIGURE 3: MTT assays of HL-60 cell line treated with a combination of doxorubicin with hippuric acid and HAN as positive control.

showed DNA fragmentation, verified by DNA ladder assay [16]. These nuclear changes were investigated in the presence and the absence of hippuric acid or HAN in the presence of cytarabine.

The degree of DNA fragmentation in the untreated control and in cells exposed to the drugs for 72 hours is shown in Figure 5. The fragmentation background in the untreated control was approximately $2.00 \pm 0.26 \%$. Both cytarabine alone and its combination of hippuric acid exhibited an increase in a similar manner through a significant increase in percentage of DNA fragmentation by $10.70 \pm$ $0.96 \%$ and $10.80 \pm 1.10 \%$, respectively, as compared to an untreated group without any marked difference as a result of the combination. The double-stranded DNA fragmentation has generally occurred with $18.90 \pm 1.33 \%$ when HL-60 cancer cells are exposed to an equal combination of cytarabine 


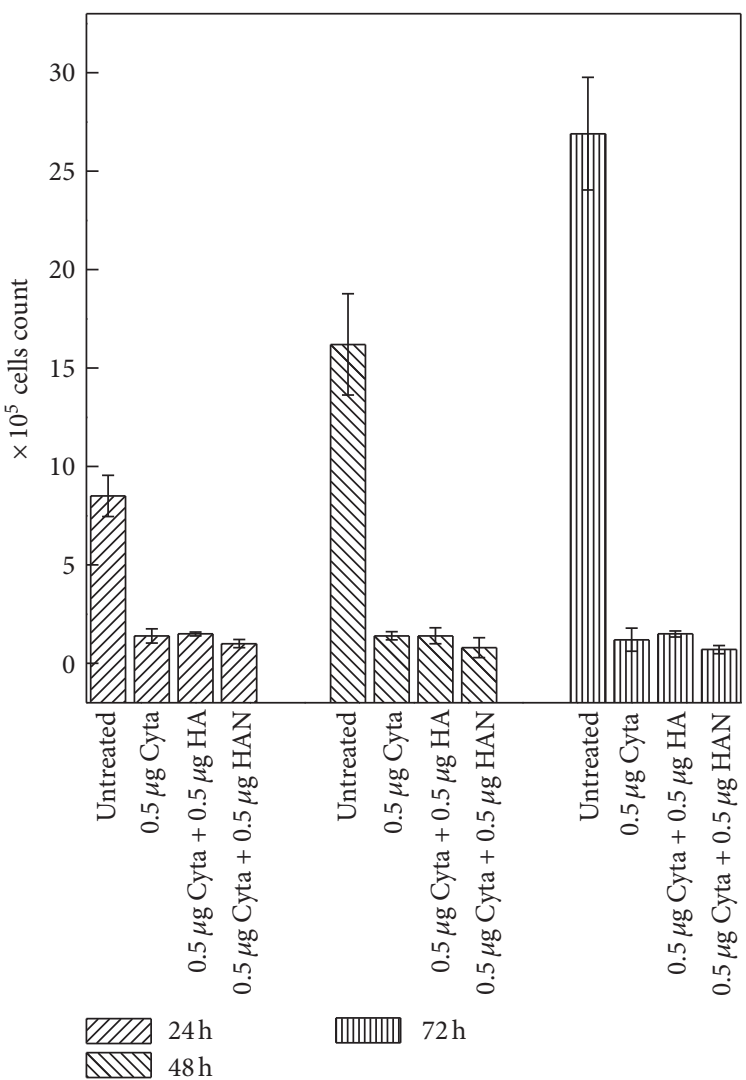

(a)

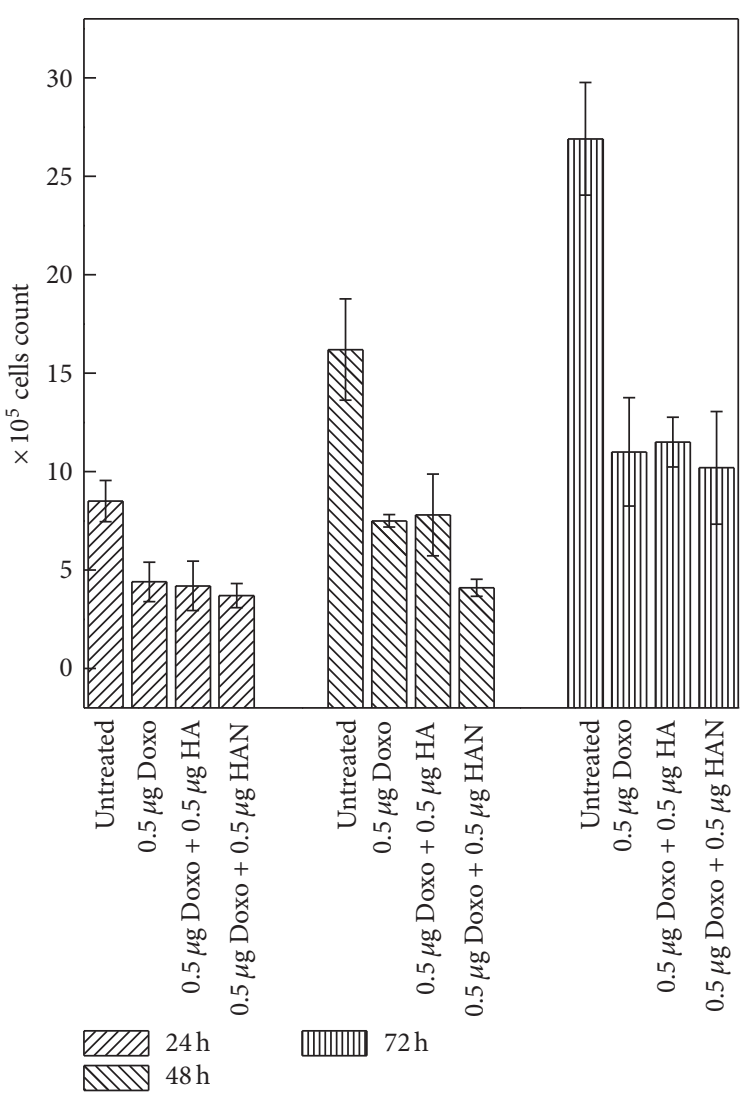

(b)

FIgURE 4: Antiproliferative assays of HL-60 cell line after, 24 48, and 72 hours of treatment with free cytarabine and a combination of free cytarabine with hippuric acid and HAN (a) and positive control using doxorubicin (b).

TABLE 4: Antimicrobial activities of hippuric acid and HAN nanocomposite against different microorganisms after 24 hours treatment ${ }^{*}$.

\begin{tabular}{lccccc}
\hline Sample & SC & BS & PA & MRSA & CA \\
\hline HA & 8 & 13 & 11 & 10 & 9 \\
HAN & 7 & 7 & 10 & 8 & 7 \\
\hline
\end{tabular}

SC: Salmonella choleraesuis; BS: Bacillus subtilis; PA: Pseudomonas aeruginosa; MRSA: methicillin-resistant Staphylococcus aureus; CA: Candida albicans; HA: hippuric acid; HAN: hippurate nanocomposite.

* Diameters of zones of inhibition were measured to nearst mm.

to HAN concentration. This result provides a rationale for the synergistic property of HAN when combined with cytarabine more than that was observed in MTT results. This indicates that drug delivery to the tumor cell was noticeably enhanced by nanocomposite with ZLH. In the nanocomposite system, however, drugs can reach the tumor cell membrane without any early decomposition, since the drug is stabilized and protected in the interlayer space of the ZLH layers. This result clearly confirmed that the intercalation reaction not only resulted in avoidance of drug denaturation but also enhanced the permeability of the drug into the target cells without any noticeable side effects [17].

10.5. Antimicrobial Activity of Hippuric Acid and Its HAN Nanocomposite. There were many previous studies reported on the antimicrobial activity of hippuric acid [18-22]. The effect of HAN against different microorganisms is reported in the present study. The work principle depends on the measurement of the diameter of inhibition zones where the increase in the inhibition zone indicating the highest antimicrobial activity. HAN exhibited antimicrobial activity against the tested organisms by showing the clear inhibition zones using the disk diffusion method. The diameters of the inhibition zone are shown in Table 4. Similar to antibiotic sensitivity testing, the antimicrobial activity of the hippuric acid against different microorganisms was determined using the disk diffusion method, employing the nanoparticles impregnated disks.

In the present study, $100 \mu \mathrm{g} / \mathrm{mL}$ suspension of hippuric acid and $25 \mu \mathrm{g} / \mathrm{mL}$ suspension of HAN were used to impregnate $6 \mathrm{~mm}$ diameter sterilized filter paper disks. The nanocomposite laden disks were placed on the surface of 


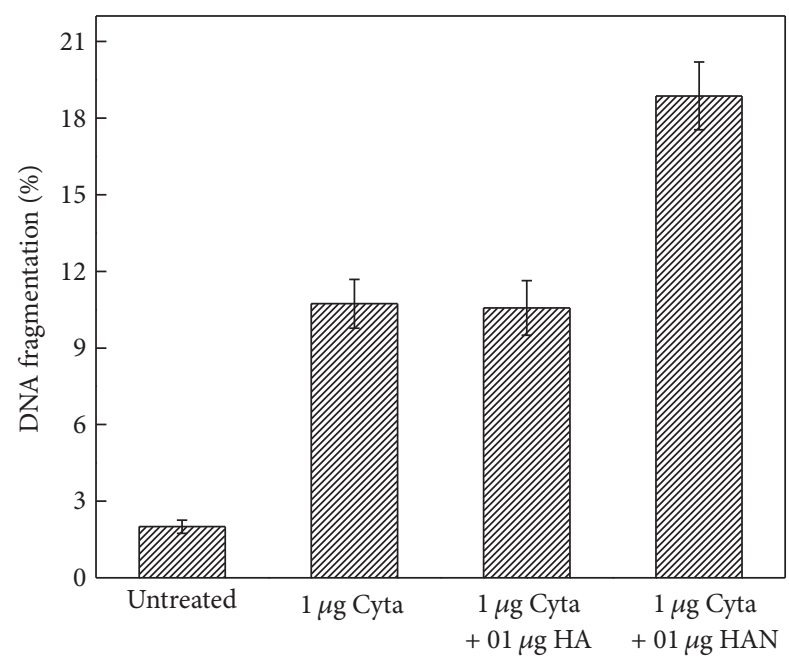

FIGURE 5: DNA fragmentation percentage of HL-60 cell line after 72 hours by cytarabine and combinations of cytarabine with hippuric acid and HAN.

LB agar plates containting the tested microorganism. The microbial suspension $\left(100 \mu \mathrm{L}\right.$ of $\left.10^{4} \mathrm{CFU} \mathrm{mL}^{-1}\right)$ was applied uniformly on the surface of the dried LB agar plates in case of bacteria or potato dextrose agar plates in case of yeast before placing the disks on the plate ( 3 plates per microorganism). The plates were incubated at $37^{\circ} \mathrm{C}$ for 24 hours. At the end of the incubation period, the average diameter $(\mathrm{mm})$ of the inhibition zone surrounding the disk was measured using a ruler with up to $1 \mathrm{~mm}$ resolution.

The most susceptible organisms to the hippuric acid were Bacillus subtilis and Pseudomonas aeruginosa. In addition, Pseudomonas aeruginosa and methicillin-resistant Staphylococcus aureus were more sensitive to HAN as compared to other micro-organisms, and this might be attributed to the smaller particle size of HAN as compared to hippuric acid alone. The small particle size of HAN allowed more drug uptake by Gram-negative bacteria. As shown in Table 4, hippuric acid and HAN show similar antimicrobial activity against all the tested organisms, although hippuric acid shows a slightly larger zone of inhibition than HAN. This might be attributed to that HAN is known of slow release of active hippuric acid.

It is worth mentioning that Pseudomonas aeruginosa and MRSA are major pathogens causing problematic infections in human and animals such as septicemia, wound, burns, and deadly infections $[23,24]$. In addition, these two pathogens are known of multidrug resistance to several classes of currently used antibiotics making the treatment process problematic and concerning $[25,26]$. Nanointercalation of $9.5 \mu \mathrm{g}$ hippuric acid (38\% of the $25 \mu \mathrm{g}$ HAN) between two zinc-layered hydroxide (ZLH) increases its efficacy and exhibits the approximate reduction of $100 \mu \mathrm{g} / \mathrm{mL}$ hippuric acid in bacterial growth after 24 hours exposure as seen in Pseudomonas aeruginosa. The application of HAN would improve control of infections caused by these pathogens by its slow release of antibacterial activity. Our results were in accordance with the prospective importance of nanoparticles in the treatment of bacterial infections and nanomedicine $[27,28]$.

\section{Conclusion}

A new nanocomposite compound in which hippuric acid is intercalated into the interlayer of zinc layered hydroxide was synthesized by direct reaction of zinc oxide aqueous suspension with anions of hippuric acid. The resulting phase pure nanocomposite was synthesized using 0.2 molar hippuric acid and had a basal spacing of $21.3 \AA$. The combination of cytarabine with HAN showed higher tumor suppression efficiency compared to cytarabine alone with $\mathrm{IC}_{50}$ values $0.165 \pm 0.070 \mu \mathrm{g} / \mathrm{mL}$. The exposure of HL-60 cancer cells to cytarabine alone resulted in $10.70 \pm 0.96 \%$ DNA fragmentation compared to $18.90 \pm 1.33 \%$ in the case of combination of cytarabine with HAN. Furthermore, the HAN nanocomposite showed antimicrobial activity against Pseudomonas aeruginosa and methicillin-resistant Staphylococcus aureus.

\section{Conflict of Interests}

The authors declare that they have no conflict of interests in this work.

\section{Acknowledgments}

The authors would like to thank the Ministry of Higher Education of Malaysia for financial support under Grant no. FRGS/1/11/SG/UPM/01/2 (Vot. 5524165) and to the Malaysian International Scholarship (MIS) for Financial support of Dr. MEZ, from the department of Microbiology and Immunology, Faculty of Pharmacy, Zagazig University, Egypt, through a postdoctors scolarship.

\section{References}

[1] V. Rives, Layered Double Hydroxides: Present and Future, Nova Science, New York, NY, USA, 2001.

[2] G. G. C. Arizaga, K. G. Satyanarayana, and F. Wypych, "Layered hydroxide salts: synthesis, properties and potential applications," Solid State Ionics, vol. 178, no. 15-18, pp. 1143-1162, 2007.

[3] K. Ladewig, P. X. Zhi, and Q. L. Gao, "Layered double hydroxide nanoparticles in gene and drug delivery," Expert Opinion on Drug Delivery, vol. 6, no. 9, pp. 907-922, 2009.

[4] S. Aisawa, "Nucleotide transport efficiency to leukemia cells by layered double hydroxide," Kagaku to Kogyo, vol. 55, no. 7, p. 809, 2002.

[5] J. H. Choy, M. Park, and J. M. Oh, "Bio-nanohybrids based on layered double hydroxide," Current Nanoscience, vol. 2, no. 3, pp. 275-281, 2006.

[6] J. H. Choy, "Biological hybrid materials for drug delivery system," Solid State Phenomena, vol. 111, pp. 1-6, 2006.

[7] J. H. Choy and M. Park, "Nanohybridization of biomolecules with layered double hydroxides and hydroxy double salts for advanced applications," Clay Science, vol. 12, pp. 52-56, 2005.

[8] M. Louer, D. Louer, and D. Grandjean, "Etude structurale des hydroxynitrates de nickel et de zinc. I. Classification 
structurale," Acta Crystallographica B, vol. 29, pp. 1696-1703, 1973.

[9] S. H. H. Al Ali, M. Al-Qubaisi, M. Z. Hussein, Z. Zainal, and M. N. Hakim, "Preparation of hippurate-zinc layered hydroxide nanohybrid and its synergistic effect with tamoxifen on HepG2 cell lines," International Journal of Nanomedicine, vol. 6, pp. 3099-3111, 2011.

[10] S. H. Al Ali, M. Al-Qubaisi, M. Z. Hussein, M. Ismail, Z. Zainal, and M. N. Hakim, "Controlled-release formulation of antihistamine based on cetirizine zinc-layered hydroxide nanocomposites and its effect on histamine release from basophilic leukemia (RBL-2H3) cells," International Journal of Nanomedicine, vol. 7, pp. 3351-3363, 2012.

[11] M. Z. Hussein, S. H. Al Ali, Z. Zainal, and M. N. Hakim, "Development of antiproliferative nanohybrid compound with controlled release property using ellagic acid as the active agent," International Journal of Nanomedicine, vol. 6, pp. 1373-1383, 2011.

[12] J. M. Andrews, "BSAC standardized disc susceptibility testing method," Journal of Antimicrobial Chemotherapy, vol. 48, no. 1, pp. 43-57, 2001.

[13] M. Yin, Y. Gu, I. L. Kuskovsky et al., "Zinc oxide quantum rods," Journal of the American Chemical Society, vol. 126, no. 20, pp. 6206-6207, 2004.

[14] S. P. Newman and W. Jones, "Comparative study of some layered hydroxide salts containing exchangeable interlayer anions," Journal of Solid State Chemistry, vol. 148, no. 1, pp. 26-40, 1999.

[15] J. M. Leclerc and R. L. Momparler, "Effect of the interval between exposures to cytarabine on its cytotoxic action on HL60 myeloid leukemic cells," Cancer Treatment Reports, vol. 68, no. 9, pp. 1143-1148, 1984.

[16] D. Y. Bouffard and R. L. Momparler, "Comparison of the induction of apoptosis in human leukemic cell lines by 2', 2'difluorodeoxycytidine (gemcitabine) and cytosine arabinoside," Leukemia Research, vol. 19, no. 11, pp. 849-856, 1995.

[17] J. H. Choy, J. S. Jung, J. M. Oh et al., "Layered double hydroxide as an efficient drug reservoir for folate derivatives," Biomaterials, vol. 25, no. 15, pp. 3059-3064, 2004.

[18] J. M. T. Hamilton-Miller and W. Brumfitt, "Methenamine and its salts as urinary tract antiseptics. Variables affecting the antibacterial activity of formaldehyde, mandelic acid, and hippuric acid in vitro," Investigative Urology, vol. 14, no. 4, pp. 287-291, 1977.

[19] D. Kaye, "Antibacterial activity of human urine," Journal of Clinical Investigation, vol. 47, no. 10, pp. 2374-2390, 1968.

[20] Y. L. Lee, J. Owens, L. Thrupp, and T. C. Cesario, "Does cranberry juice have antibacterial activity?" Journal of the American Medical Association, vol. 283, no. 13, p. 1691, 2000.

[21] I. Ofek, J. Goldhar, D. Zafriri, H. Lis, R. Adar, and N. Sharon, "Anti-Escherichia coli adhesin activity of cranberry and blueberry juices," The New England Journal of Medicine, vol. 324, no. 22, p. 1599, 1991.

[22] R. Raz, B. Chazan, and M. Dan, "Cranberry juice and urinary tract infection," Clinical Infectious Diseases, vol. 38, no. 10, pp. 1413-1419, 2004.

[23] N. Mesaros, P. Nordmann, P. Plésiat et al., "Pseudomonas aeruginosa: resistance and therapeutic options at the turn of the new millennium," Clinical Microbiology and Infection, vol. 13, no. 6, pp. 560-578, 2007.

[24] A. R. Naylor, P. D. Hayes, and S. Darke, "A prospective audit of complex wound and graft infections in Great Britain and
Ireland: the emergence of MRSA," European Journal of Vascular and Endovascular Surgery, vol. 21, no. 4, pp. 289-294, 2001.

[25] J. N. Sharpe, E. H. Shively, and H. C. Polk, "Clinical and economic outcomes of oral linezolid versus intravenous vancomycin in the treatment of MRSA-complicated, lowerextremity skin and soft-tissue infections caused by methicillinresistant Staphylococcus aureus," American Journal of Surgery, vol. 189, no. 4, pp. 425-428, 2005.

[26] D. M. Livermore, "Multiple mechanisms of antimicrobial resistance in Pseudomonas aeruginosa: our worst nightmare?" Clinical Infectious Diseases, vol. 34, no. 5, pp. 634-640, 2002.

[27] A. J. Huh and Y. J. Kwon, "Nanoantibiotics': a new paradigm for treating infectious diseases using nanomaterials in the antibiotics resistant era," Journal of Controlled Release, vol. 156, pp. 128-145, 2011.

[28] S. Parveen, R. Misra, and S. K. Sahoo, "Nanoparticles: a boon to drug delivery, therapeutics, diagnostics and imaging," Nanomedicine, vol. 8, no. 2, pp. 147-166, 2012. 

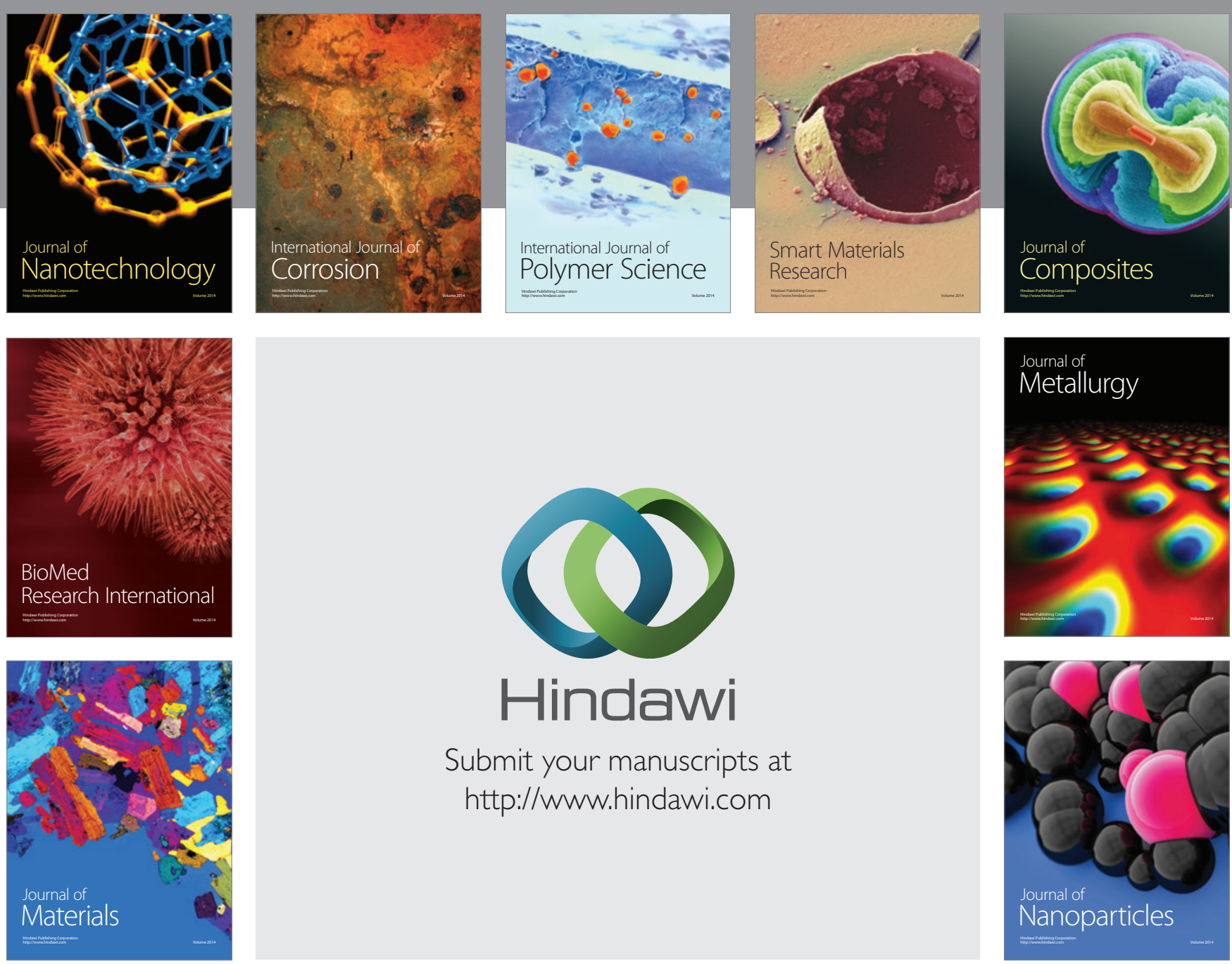

Submit your manuscripts at http://www.hindawi.com
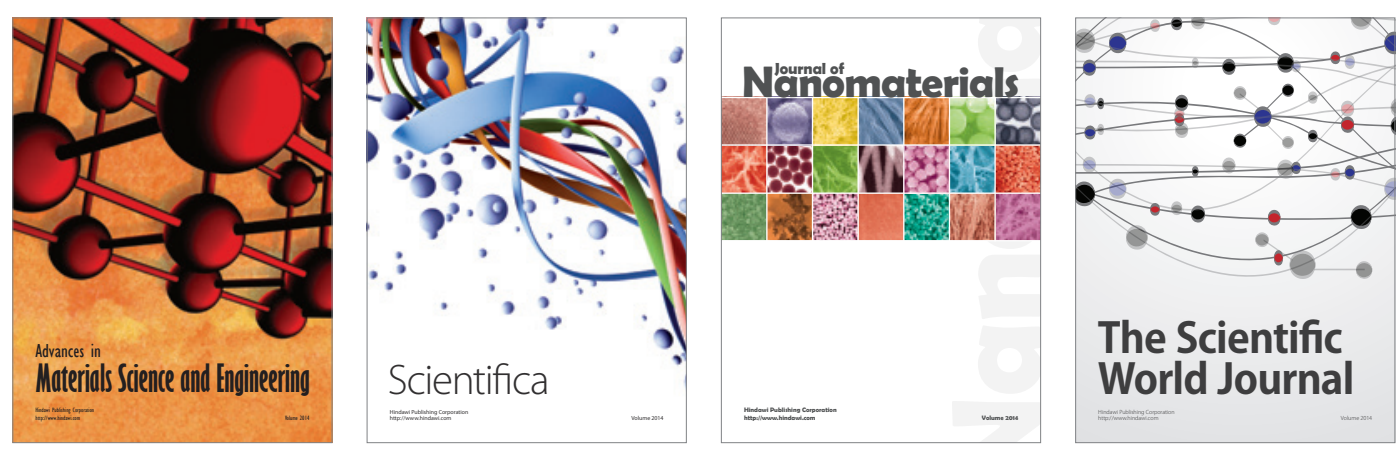

\section{The Scientific World Journal}
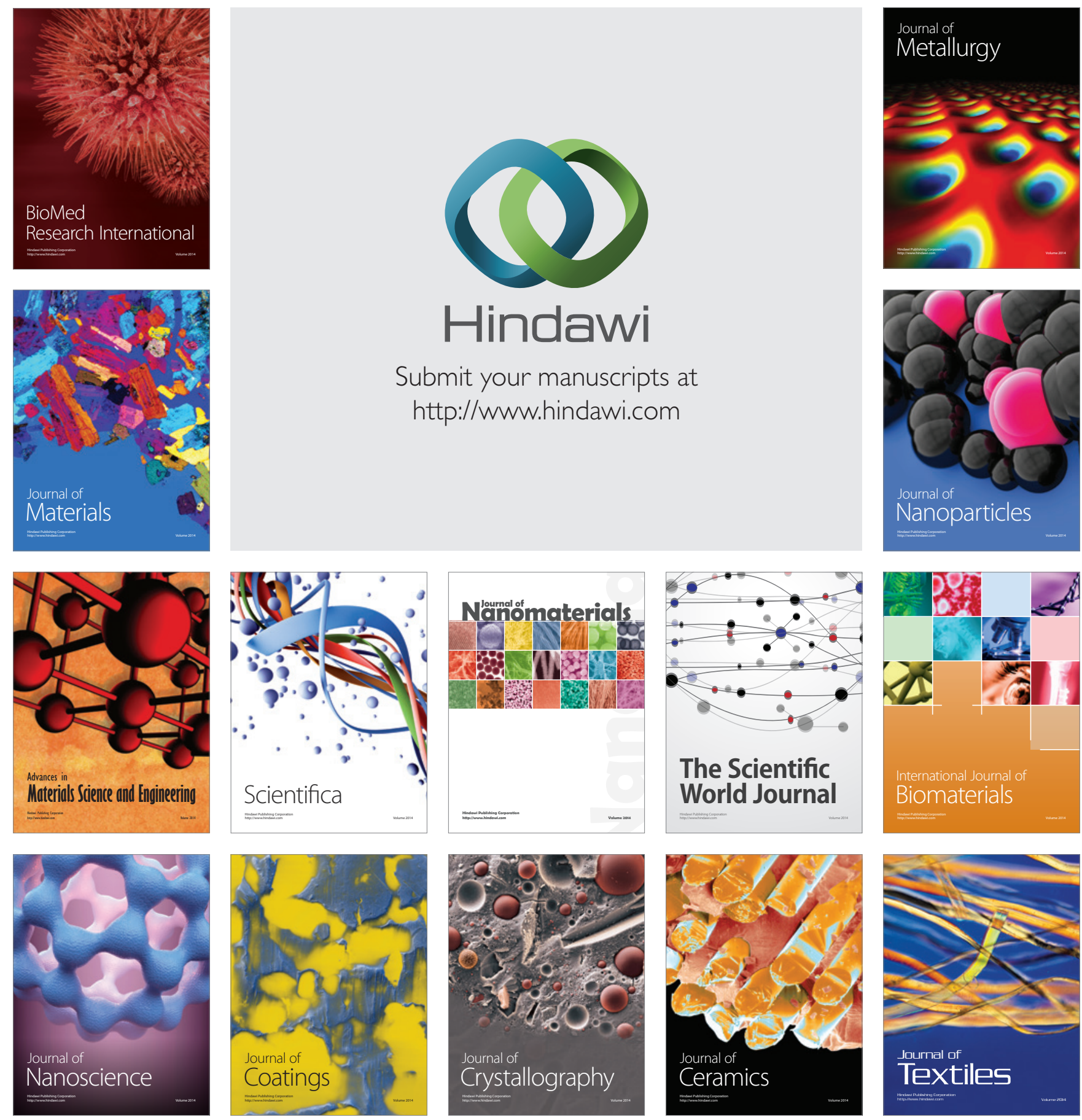